\title{
DOES THE PARETO PRINCIPLE APPLY IN THE INNOVATION FIELD IN ROMANIA?
}

\author{
Alina BABA ${ }^{1}$ \\ ${ }^{1}$ Doctoral School of Economic Sciences, Faculty of Economic Sciences, University \\ of Oradea, Oradea, Romania, baba.alina79@gmail.com
}

\begin{abstract}
The technological transfer entities can obtain income by establishing robust partnerships with the business environment and using the fiscal facilities offered by the region where they produce the innovation, applying for nonrefundable funds, attracting individual donors, charging a membership contribution to the organization members, exploitation of innovation produced by the sale of intellectual property. A robust innovation ecosystem is based on public and private investments which complement each other to reduce the risks and to divide profits by increasing the capacity of innovation and technological transfer of the technological transfer entities. The Gauss distributions are continuous probability distributions. These are" normal" distributions which illustrate the likelihood that a certain event takes place. A gauss distribution has the shape of a bell with most values distributed around the average value and can be fully described by variance and mean. A classic example is the distribution of patents value or profit obtained because of sale of intellectual property rights. The Pareto-type distributions are found in other phenomena around us, such as the size of economic entities follows a Pareto distribution. Pareto-type distributions are more suitable to describe the economic phenomena than the Gauss distributions, for instance, $80 \%$ of the world richness is held by $20 \%$ of population (principle $80-20$ which means $80 \%$ of results are caused by $20 \%$ of causes). The innovation phenomenon is deeply systemic, multifactorial, multifunctional, dynamic and complex, determined by the whole socio-economic background which influences the innovation ecosystem. Therefore, its study for the highlighting of the intervention opportunities at level of fiscal and financial policies, but also at operational level, requires an adequate, multilateral and complete systemic approach.
\end{abstract}

Keywords: technological transfer; innovation; finances

JEL Classification: $\mathrm{O} 32$

\section{Introduction}

In the market economy of innovation, which is dynamic and in which the participants are autonomous and efficient, there is a major difference between those who fund and those who lead technological transfer entities. Seldom, it happens that one and the same person funds the activity of a technological transfer entity and at the same time, is its creator or manager. On the other hand, for the entities which create innovation to appear and develop, it is necessary that two types of characters collaborate well. Sometimes, we are in the situation of information asymmetry, which means that the managers of the technological 
transfer entities hold much more specialised/scientific information than the possible funders of innovation. On the other hand, there is a moral hazard, which means high risk (above a justified limit) which is undertaken by those who fund the technological transfer entities. The implication of these facts is that finally, the financing costs of ETT will be higher than in ordinary companies, and the negative impact is especially on start-ups and spin-offs which only deal with research and development and unlike the large industrial companies which hold production departments, they do not afford to use own funds for multiplication of the results of the research-development-innovation activity.

As for the situation of start-ups on the technological transfer market, it is even more complicated. First of all, they are facing all the problems which a newly founded entity has, to which we can add the need for presenting a sufficiently wellstructured business plan which can attract financing and which fully answers the reservations which the financiers - who do not understand the scientific or innovation problems - normally have. In addition, we have to think that the national states or European Union are trying to come up with solutions and opportunities of public policies in the field (such as, the differentiated taxation of technological transfer companies, but also the access to dedicated financing lines). In conclusion to the above, even if we need to understand that the financial mechanisms of technological transfer entities are different from those of the other companies, we need to analyse why they are different and what these differences are.

\section{Literature review}

In general, investments in innovation have costs which are classified in the following categories: costs for research and development (R\&D), capital expenditure for equipment, staff training costs, costs for multiplication of innovation, design costs, marketing costs and costs for the advertising of innovation produced. Depending on the nature of innovation and the technology used, these costs can differ, but on average, the costs for research-developmentinnovation represent over $50 \%$ of total, and from this category the staff costs (researchers, engineers etc.) represent $50 \%$. This means that from the total costs of a technological transfer entity, over $25 \%$ of funds are used only for the payment of researchers. In addition, we have to take into account also the salary costs of technicians, technologists and workers involved in the production stage, the salary costs for the design, marketing and advertising stage, for the management and brokerage of innovation produced.

A highly qualified human resource is essential for the functioning of a technological transfer entity, and in its absence (by migration to other companies or by dismissal), the entity becomes incapable of fulfilling its role. On the other hand, because of potential volatility of human research resource, the research and development costs will follow a model of cost adjustment so that the technological transfer entity tries to maintain itself at a sub-optimal level of applied scientific production. (Lach, S. and Schankerman, M. (2008). Of course, it is likely that the entity contacts research and development activities from outside, but if it renounces its own research, it will turn into an ordinary company. What we can see from the practice of the latest decades is that, on one hand, most of ETTs increase their research and development costs to a certain extent, and on the 
other hand, the demand of research-development-innovation services increases towards the technological transfer entity.

The analysis of finances of technological transfer entities has to take into account the less predictable nature of the profit which can be generated; in other words, a research idea can be promising, but there is a long way to the marketing of the product and the reception of profit. In order to analyse accurately the need of the market economy which can be satisfied by the innovation which the ETT could produce, we studied data from varied sources (Scherer, F.M. (1998): the portfolios of patents from the American universities, the results of a study on German patents, the stock exchange profits from three samples of start-ups in high technology field. In this analysis, we noticed a variation of distributions of profits from innovation, some of them are close to normal distributions, while others are closer to a Pareto type distribution in which there is no variance. In this latter case, we have examples of successful innovative companies (the giants such as Microsoft, Google, Facebook etc.) which obtain a very high profit compared to the invested amount and are" models" for the business world, but for each of them, there are millions of companies which fail. Practically, in this situation the classical risk evaluation methods cannot work and we cannot apply an analysis of the diversification strategy of technological transfer entities.

The variance of distribution is calculated by the following formula:

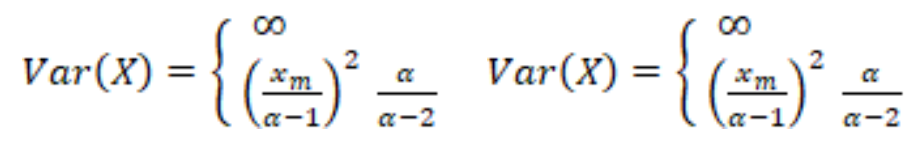

if $\alpha \leq 2$ there is no variance.

Another mechanism for financing technological transfer entities is the leverage effect by which the entities can use borrowed capital for the purchase of assets and for development. But what is the theoretical model of financing of technological transfer entities? In order to answer this question, we will start from the neo-classical model of marginal profit (difference between the marginal cost and the marginal income).

According to the following formula:

$$
M P K=c_{t}=p_{t}-\frac{(1-\delta)}{(1-\rho)} p_{t+1}
$$

The marginal product of capital (MPK) which is used for a period of time $t$ is equal to its price minus what the ETT receives from the sale of capital until time $t+1$ and which in this formula is represented by $(1-\delta) p t+1$ from which we extract the rate of return $\mathrm{P}$ which is received by the investor after the taxes of the entity are paid (Bronwyn H. 2009).

The formula above contains implicitly three factors that will affect the finances of a technological transfer entity: the rate by which the knowledge capital thus created is depreciated or becomes outdated, the rate of return requested and the rate of change of the real price for the research-development activity (the input price of the research-development activity is directly proportional to the output price of the company) (Bronwyn H. 2009). 
The capital cost for the beneficiary of innovation will include both the investment cost and the adjustment by interest and depreciation rates, the capital earnings and taxes. It is obvious that the marginal product of capital increases when $(1-\delta)$ increases. This happens also when (1-P) decreases, for instance, as a result of reducing taxes for $R \& D$ activities.

\section{Hypotheses: The PARETO principle in the innovation field in Romania and in European Union}

In order to answer the question if the Pareto principle applies in innovation field in Romania and European Union, we conducted an analysis of the Pareto distribution principle regarding the patents obtained in Romania during the years 2018, 2019 and 2020 in five fields: agriculture, environment, biotechnology, IT and food. From this research, we can see that most patents obtained are in environmental field, which represents 4.81\% (year 2018), 4.68\% (year 2019) and $4.82 \%$ (year 2020) of total number of patents.

Table 1: Number of patents in Romania for the analysed period 2018-2020

\begin{tabular}{|l|l|l|l|l|}
\hline No. & Field & $\mathbf{2 0 1 8}$ & $\mathbf{2 0 1 9}$ & $\mathbf{2 0 2 0}$ \\
\hline 1. & Agriculture & 5 & 12 & 4 \\
\hline 2. & Environment & 35 & 39 & 43 \\
\hline 3. & Biotechnology & 1 & 0 & 0 \\
\hline 4. & IT & 3 & 0 & 2 \\
\hline 5. & Food & 3 & 0 & 2 \\
\hline 6. & All fields & 727 & 834 & 892 \\
\hline
\end{tabular}

Source: Data processed according to the information available at https://ro.espacenet.com

This shows that in the environmental field there are persons who are interested in innovation and technological progress to whom a large number of other actors is added. We are thinking first of all of a large number of companies to which we can add governmental organizations (universities and research institutes) as well as non-governmental organizations which create an ecosystem favourable to research and innovation. We must not forget that Romania has inherited from the Communist age a high number of environmental problems, population and media have become more and more interested in these issues and the European Union offers every year large amounts of money for the resolution of environmental issues (including for research, development and innovation).

The second field which is well-appreciated is agriculture. This field excelled in the year 2019. However, we can easily see that there are few patents obtained during the analyzed period in the smart specialization fields in Romania. We would have expected that the number of patents in IT field was much higher, taking into account that this field probably represents the top field of Romanian economy, if we were to consider just the weight of this field in the gross domestic product. The same thing can be said about biotechnologies, which from the point of view of 
investment cost ratio to the benefits achieved, represents the most profitable field. Chart 8 illustrates this discrepancy.

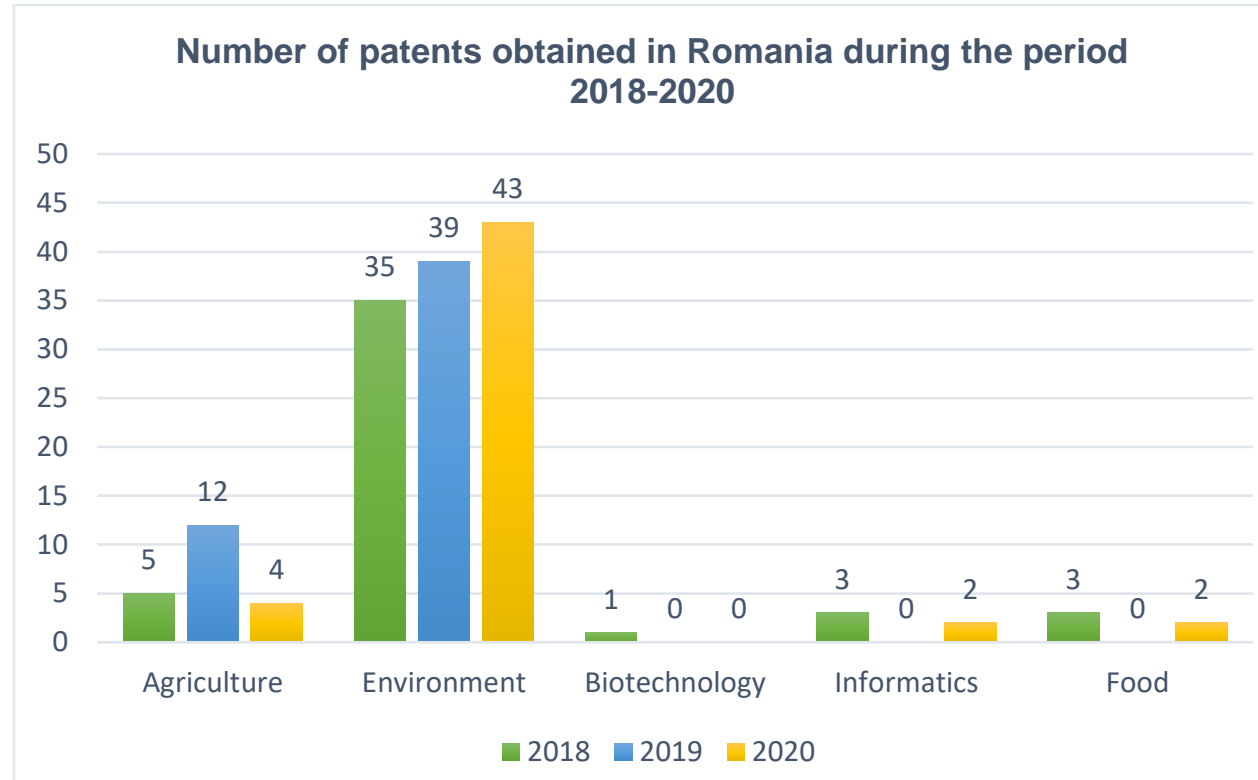

Figure 1: Number of patents in Romania during the period 2018-2020 for the five fields analysed

Source: Data processed according to the information available at https://osim.ro/

In order to make a benchmark analysis between Romania and the European Union, we will make a parallel with the number of patents obtained at European level in the same smart specialization fields.

Table 2: Number of patents published in English in EU during the analyzed period 2018-2020

\begin{tabular}{|l|l|l|l|l|}
\hline No. & Field & $\mathbf{2 0 1 8}$ & $\mathbf{2 0 1 9}$ & $\mathbf{2 0 2 0}$ \\
\hline 1. & Agriculture & 10304 & 10560 & 17650 \\
\hline 2. & Environment & 10766 & 12467 & 16570 \\
\hline 3. & Biotechnology & 10200 & 10300 & 10500 \\
\hline 4. & IT & 3371 & 2219 & 1609 \\
\hline 5. & Food & 10050 & 11376 & 10456 \\
\hline
\end{tabular}
https://ro.espacenet.com 


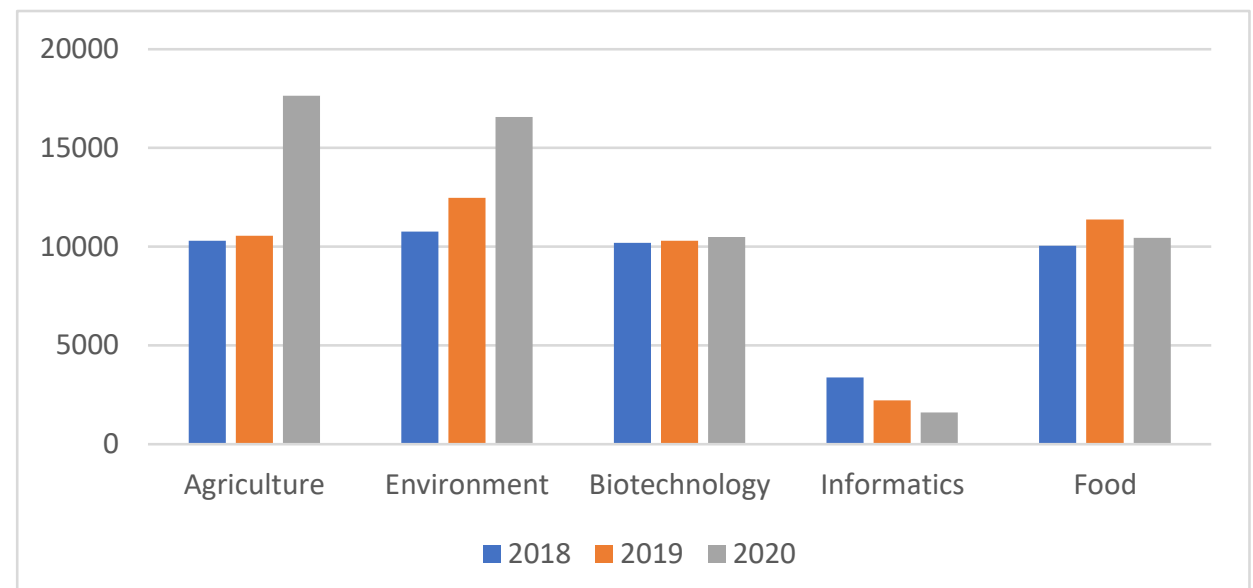

Figure 2: Number of patents in European Union during the period 2018-2020 for the five analysed fields

Source: Data processed according to the information available at https://worldwide.espacenet.com/

According to Figure 2 we can see that the same fields: agriculture and environment are on top positions. In the year 2020 we can see a marked increase of patents in agriculture and environmental fields, which shows that there is a capital disposed to invest in innovation produced for these fields. In the other fields studied, we can see a limited increase for biotechnologies and a decrease of innovation produced in IT and food fields. We can see that four of the five fields, which are agriculture, environment, biotechnologies and food are grouped according to the number of patents in EU, which gives the image of a balanced development.

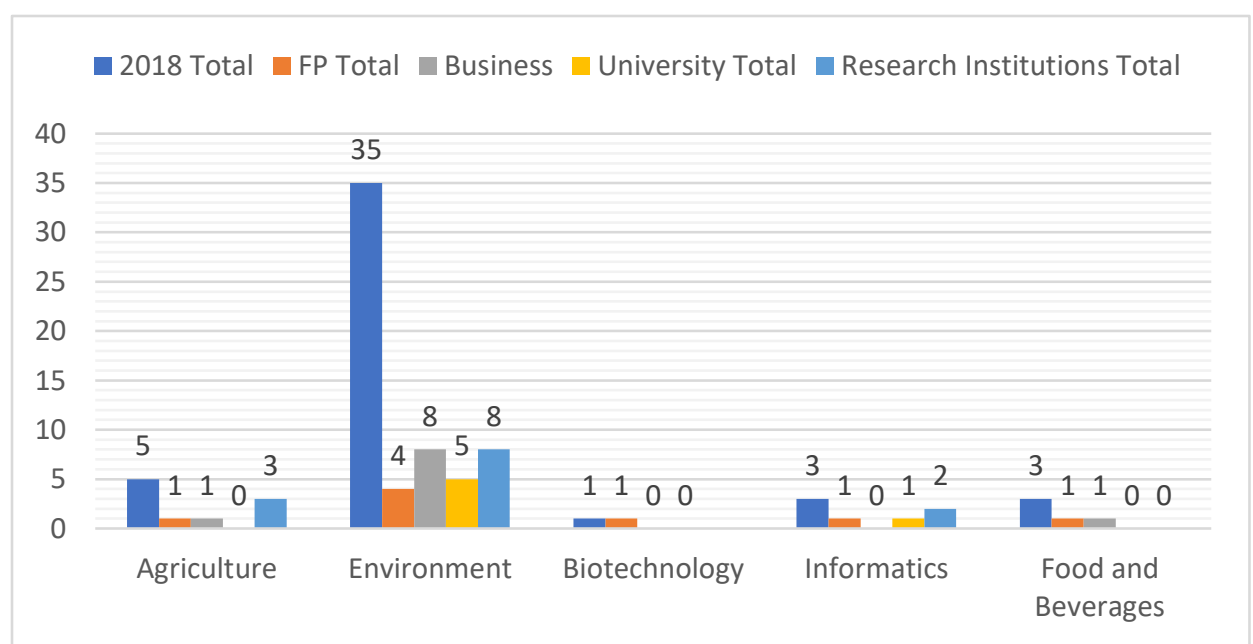

Figure 3: Distribution of patents in the year 2018 in Romania

Source: Data processed according to the information available at https://osim.ro/ 


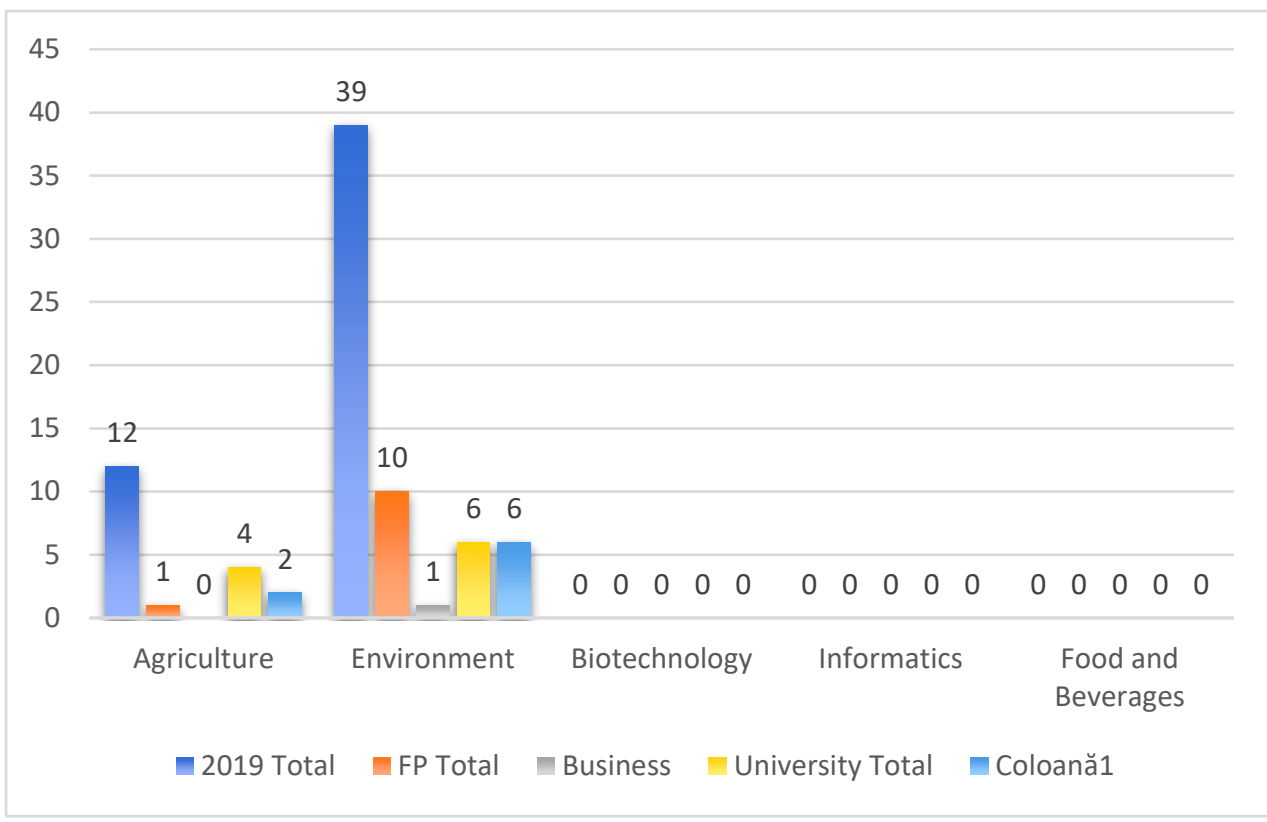

Figure 4: Distribution of patents in 2019 in Romania

Source: Data processed according to the information available at https://osim.ro/

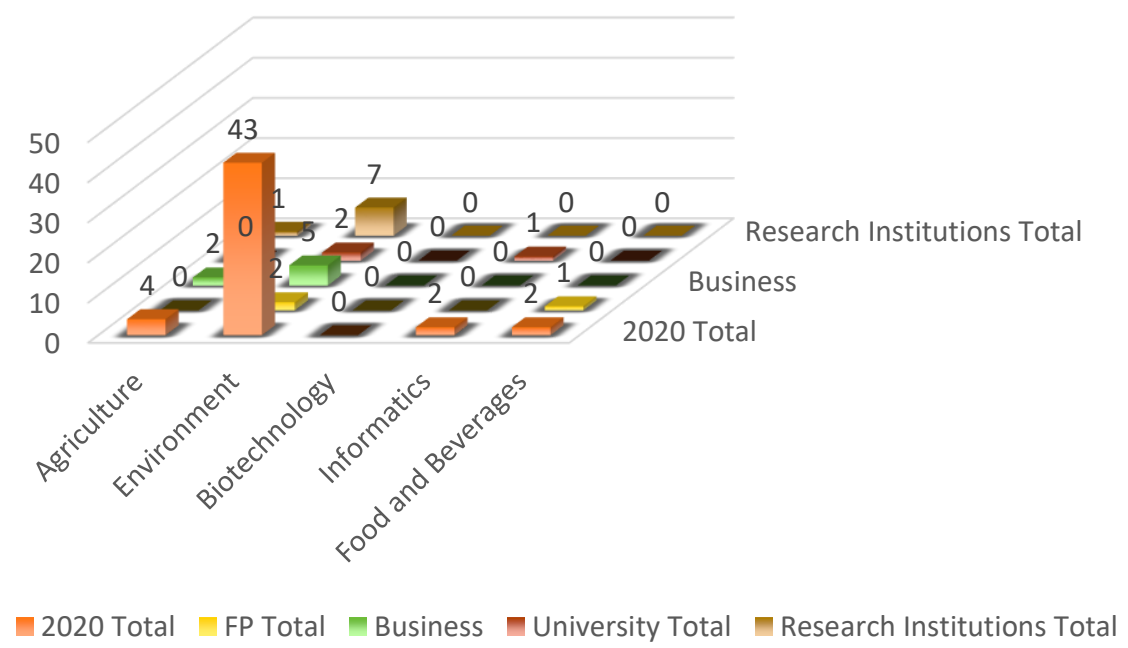

Figure 5: Patents of Romania during the period 2018-2020

Source: Data processed according to the information available at https://osim.ro/ 


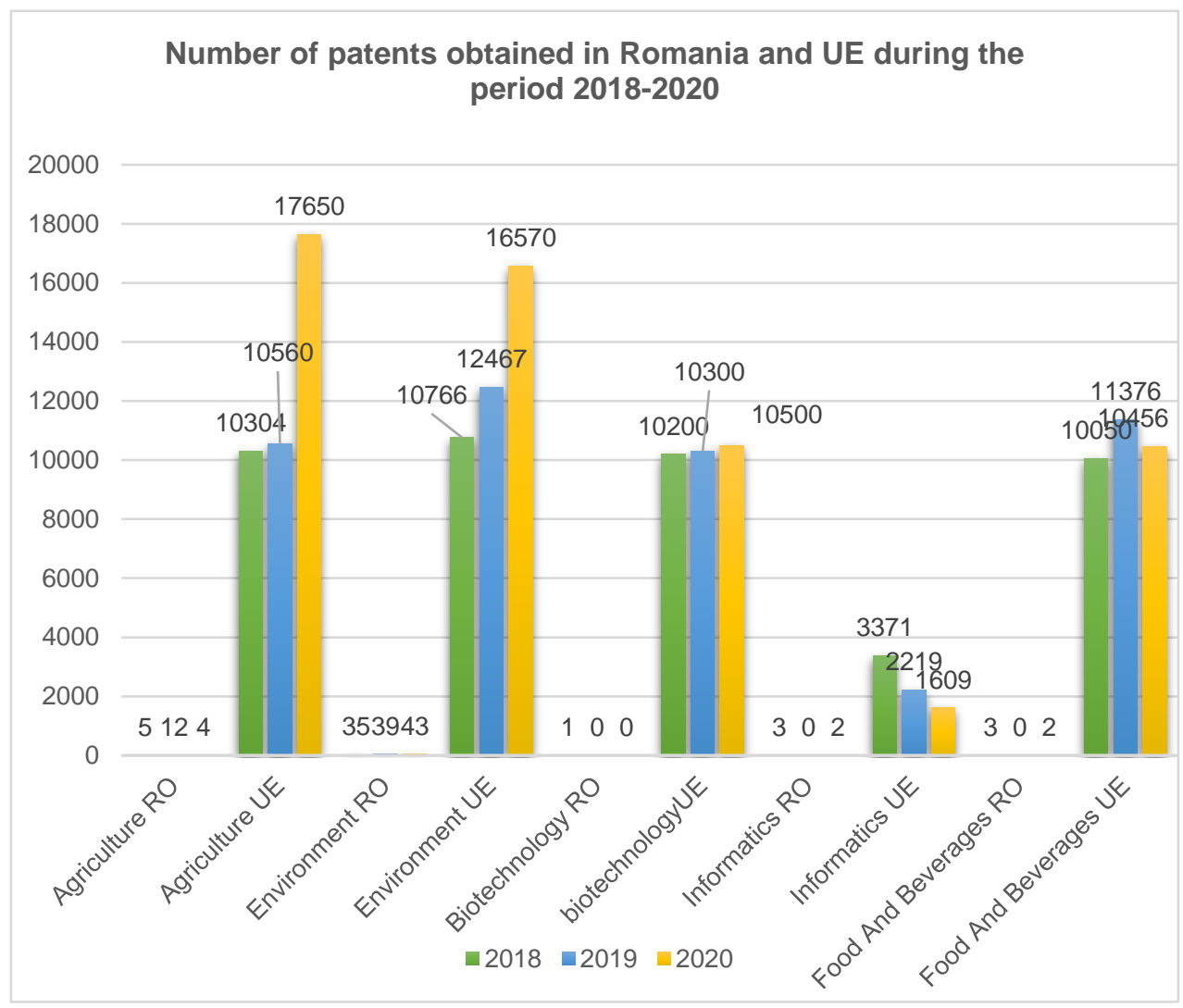

Figure 6: Patents of Romania-EU during the period 2018-2020

Source: Data processed according to the information available at https://osim.ro/; https://patentscope.wipo.int/search/en/search.jsf

\section{References:}

1. Bronwyn H. Hall (2009), The 'funding gap': financial markets and investment in innovation. The New Economics of Technology Policy. Edward Elgar Publishing; 2009.

2. Grossman GM, Helpman E. (1991), Innovation and growth in the global economy. MIT press; 1991.

3. Guidelines On Programming For Innovation And The Implementation Of The EIP For Agricultural Productivity And Sustainability (2014) ec.europa.eu. European Commission - Directorate-General For Agriculture And Rural Development; 2014, Available from:

https://ec.europa.eu/eip/agriculture/sites/default/files/pb guidelines eip implement ation 2014 en.pdf

4. Egidi M, Marris RL, Viale R, editors.(1992), Economics, bounded rationality and the cognitive revolution. Edward Elgar Publishing; 1992.

5. Modigliani F, Miller MH. (1958), The cost of capital, corporation finance and the theory of investment. The American economic review. 1958 Jun 1;48(3):261-97. 
6. Modigliani F, Miller MH.(1963), Corporate income taxes and the cost of capital: a correction. The American economic review. 1963 Jun 1;53(3):433-43.

7. Drucker P.(2014), Innovation and entrepreneurship. Routledge; 2014 Sep 15.

8. Ramanathan K. An Overview of Technology Transfer and Technology Transfer Models [Internet]. http://tto.boun.edu.tr/. Boğaziçi University Technology Transfer Office; Available from:

http://tto.boun.edu.tr/files/1383812118 An\%20overview\%20of\%20TT\%20and\%20 TT\%20Models.pdf

9. Saul Lach, Mark Scankerman (2008), Incentives and invention in universities. The RAND Journal of Economics; Volume 39, Issue 2, Summer 2008.

10. Scherer M. Frederic (1998), The Size Distribution of Profits from Innovation. Annales d'Economie et de Statistique, 1998, no. 49/50, pp. 495-516.

11. Study On Dynamics Of Labour Market For The Main Employing Industries In Romania During The Period 2016-2017. www.piarom.ro. Patronatul Investitorilor Autohtoni PIAROM; Available from:

https://www.piarom.ro/studiu-privind-dinamica-pietei-muncii-la-nivelul-principalelorindustrii-angajatoare-din-romania-in-perioada-2016-2017/ 